УДК 622.831

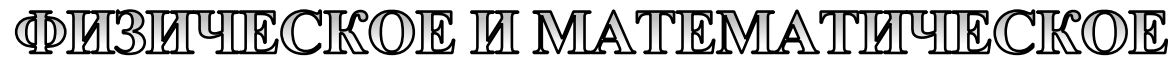

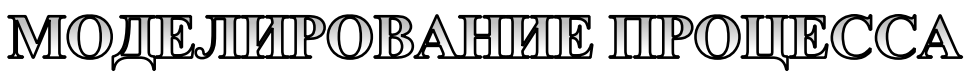

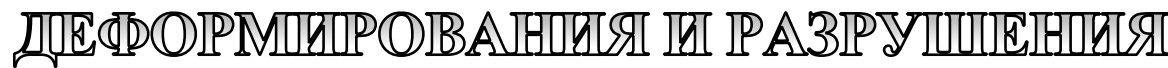 MUE
}

И.С. Ломакин, Горный институт УрО РАН

А.А. Цаюков, Горный институт УрО РАН

А.В. Евсеев, Горный институт УрО РАН

Для цитирования:

Ломакин И.С., Цаюков А.А., Евсеев А.В. Физическое и математическое моделирование процесса деформирования и разрушения междукамерных целиков // Вестник Пермского федерального исследовательского центра. - 2021. - № 1. - C. 47-53. https://doi.org/10.7242/2658-705X/2021.1.4

Подземная добыча водорастворимых руд сопряжена с необходимостью защиты рудников от затопления. Снижение рисков возникновения аварийных ситуаций на горнодобывающих калийных предприятиях Пермского края посредством оперативного реагирования на изменение состояния недр и организации соответствующих мер защиты способствует безопасному недропользованию и развитию региона.

В статье представлены основные результаты исследования, посвященного экспериментальному и теоретическому обоснованию использования относительной поперечной деформации междукамерных целиков в качестве информативного параметра, позволяющего оперативно оценивать состояние несущих элементов подземных сооружений для условий Верхнекамского месторождения солей.

Экспериментальные исследования состояли в физическом моделировании процесса деформирования и разрушения целиков на основе лабораторных испытаний кубических соляных образцов большого размера на одноосное сжатие с регистрацией их деформированного состояния. Теоретические исследования включали математическое описание результатов лабораторных экспериментов и определения параметров модели среды, достоверно описывающей все этапы деформирования соляных образцов. С целью получения оценок значений относительных поперечных деформаций целиков, при которых происходит потеря их несущей способности, выполнена

* Статья подготовлена при финансовой поддержке гранта РФФИ № 17-45-590681 p_a «Экспериментально-теоретические подходы к оценке долговременной устойчивости подземных горнотехнических объектов».

Работа выполнена в рамках государственного задания; номер государственной регистрации темы AAAA-A18-118040690032-2. 


адаптация разработанной модели среды применительно к опорным
элементам очистных выработок с учетом их реальных размеров и
геометрической фрормы.

Ключевые слова: соляные породы, междукамерные целики, математическое моделирование, критерий прочности, разрушение, поперечная деформация, несущая способность.

Одной из главных задач обеспечения безопасных условий ведения горных работ при отработке водорастворимых руд является сохранение сплошности водозащитной толщи (ВЗТ), отделяющей водоносные горизонты от продуктивной толщи. В ряде случаев это достигается применением камерной системы разработки с поддержанием вышележащей толщи пород на ленточных междукамерных целиках. Порой технологические параметры камерной системы разработки (ширина камер и целиков, вынимаемая мощность и т.д.), определенные в соответствии с действующими на месторождениях нормативными и методическими документами $[4,6,7,9]$ или на основании научных исследований $[8,10,12,13]$, не обеспечивают заданный срок службы опорных элементов подземных сооружений.

В пределах отрабатываемых площадей Верхнекамского месторождения солей (ВКМС) на земной поверхности закладывается сеть профильных линий для контроля состояния подработанного массива. По оседаниям и горизонтальным сдвижениям грунтовых реперов судят о деформационных процессах в подрабатываемом массиве. Основная проблема такого подхода заключается в запаздывании процессов сдвижения земной поверхности относительно начала разрушения целиков в руднике, что порой не позволяет своевременно принять необходимые меры для обеспечения сохранности водозащитной толщи, а также в ограниченном количестве профильных линий, вызванных высокой стоимостью их заложения, порой труднодоступностью и занятостью территории. Вовлечение в одновременную отработку двух и более пластов еще больше усложняет эту задачу.
В этой связи важным аспектом безопасности горных работ является достоверная оценка и прогноз устойчивого состояния опорных элементов подземных сооружений.

В настоящем исследовании в качестве информативного показателя, характеризующего стадию деформирования соляных пород, рассматривалась поперечная деформация [1]. При переходе в запредельную стадию нагружения квазипластичных соляных пород происходит их разрушение, сопровождающееся интенсивным растрескиванием, при этом коэффициент поперечного деформирования резко увеличивается. Таким образом, контроль поперечной деформации может использоваться для оценки характера деформирования и стадии разрушения соляных пород.

$\mathrm{C}$ целью решения поставленной задачи выполнено физическое моделирование процесса деформирования и разрушения междукамерных целиков в лабораторных условиях по схеме одноосного сжатия кубических соляных образцов большого размера (300 мм) с контролем продольной и поперечной деформаций [5]. Отличительной особенностью этих экспериментов являлся контроль поперечных деформации образца в центральном сечении с использованием системы глубинных и контурных марок.

Испытание проводилось на гидравлическом прессе ToniNorm с максимальной нагрузкой 5000 кН. Контроль деформаций образца в процессе испытаний осуществлялся с помощью бесконтактной трехмерной оптической системы Vic-3D фирмы «Correlated Solutions», имитирующей использование экстензометра на поверхности образца. Применение данной системы 
обусловлено высокой эффективностью и точностью измерения, основывающейся на методе корреляции цифровых изображений. Метод позволяет восстанавливать поле векторов перемещений на поверхности исследуемых образцов или элементов конструкций путем сопоставления опорного изображения (фотографии объекта в исходном состоянии) с изображениями, снятыми в процессе нагружения.

По результатам лабораторных экспериментов получены графики деформирования образцов соляных пород крупных размеров в зависимости от нагрузки, а также распределения деформаций в образцах. Соотношение продольных и поперечных деформаций соляных пород, установленное по результатам физического моделирования, представлено на рис. 1.

Теоретическое описание процесса деформирования и разрушения соляных образцов больших размеров проводилось в трехмерной постановке на основе упругопластической модели среды с линейным изотропным упрочнением при ассоциированном законе пластического течения с использованием модифицированного критерия прочности Боткина и Миролюбова [3]. Численное решение задачи осуществлялось методом конечных элементов с дискретизацией области решения 8-узловыми изопараметрическими элементами гексаэдрической формы [14]. Решение систем нелинейных конечно-элементных уравнений вы- полнялось методом начальных напряжений по модифицированной схеме НьютонаРафсона в инкрементальной форме с постоянной матрицей жёсткости системы [15]. Численное интегрирование пластических определяющих соотношений выполнялось по неявной схеме алгоритма обратного отображения [11]. В результате была получена откалиброванная модель среды, с высокой степенью точности описывающая все этапы деформирования кубического образца больших размеров.

Численное моделирование процесса деформирования и разрушения опорных элементов подземных сооружений на Верхнекамском месторождении солей состояло в адаптации модели среды, достоверно описывающей лабораторные эксперименты, применительно к междукамерным целикам реальных размеров с целью оценки значений относительных поперечных деформаций, при которых происходит потеря их несущей способности.

Ввиду выраженного проявления реологических свойств соляных пород потеря несущей способности целиков реализуется преимущественно за счёт снижения значения предела прочности на одноосное сжатие [2]. В этой связи оценка относительных поперечных деформаций, при которых происходит потеря несущей способности МКЦ, производилась путём постепенного уменьшения их предела прочности на сжатие.

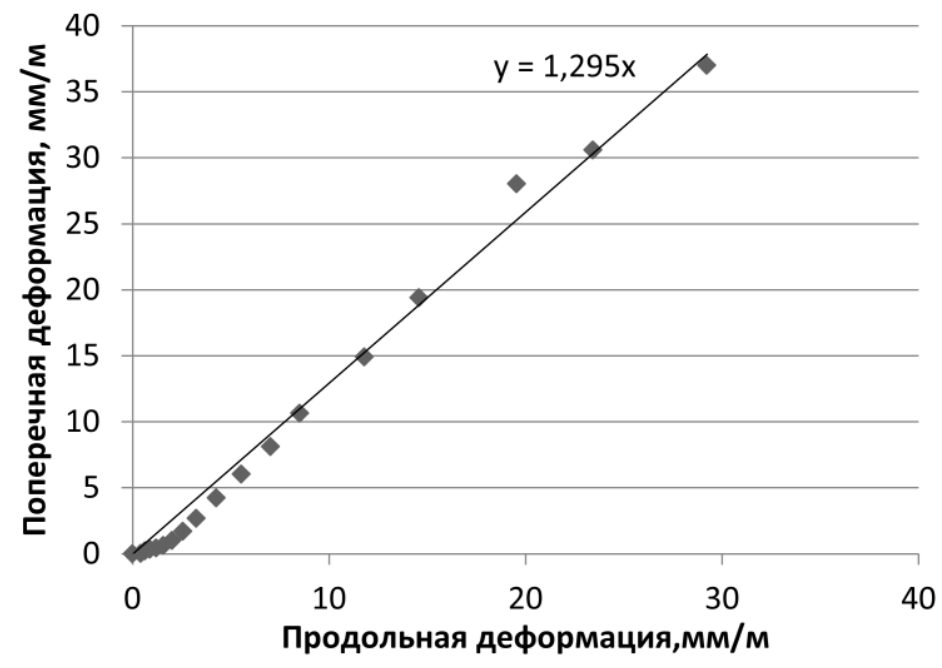

Рис. 1. Соотношение продольных и поперечных деформаций при одноосном сжатии образиов больших размеров (300 мм) 
Компьютерное моделирование проводилось в 2D-постановке, основанной на конечно-элементном подходе с использованием плоских симплекс-элементов. Рассматривался типичный для Верхнекамского месторождения двухпластовый камерный блок продуктивных сильвинитовых пластов АБ и Кр II, отработанный комбайнами «Урал-20Р» (рис. 2). Строение продуктивной толщи принималось однородным. Мощность технологического междупластья составляла 3,9 м. Принципиальная расчётная схема показана на рис. 3. Очистные камеры и междукамерные целики на рабочих пластах отмечены как «верхний» (АБ) и «нижний» (Кр II) соответственно. Параметры камерного блока представлены в табл. 1. Исходные механические свойства пород приняты по калибровочной модели разрушения соляных образцов больших размеров и приведены в табл. 2. Шаг изменения предела прочности составлял 0,1 МПа. В расчётах определялась горизонтальная конвергенция камер на обоих рабочих пластах. Моделирование продолжалось до тех пор, пока разрушением не была охвачена большая часть целиков.

По результатам вычислительных экспериментов определена динамика развития зон пластичности (разрушения) в междукамерных целиках (рис. 4). Уменьшение предела прочности с $15 \mathrm{MПа} \mathrm{до}$ 9 МПа не приводит к значимому развитию зон пластичности в МКЦ. Последующее изменение предела прочности на

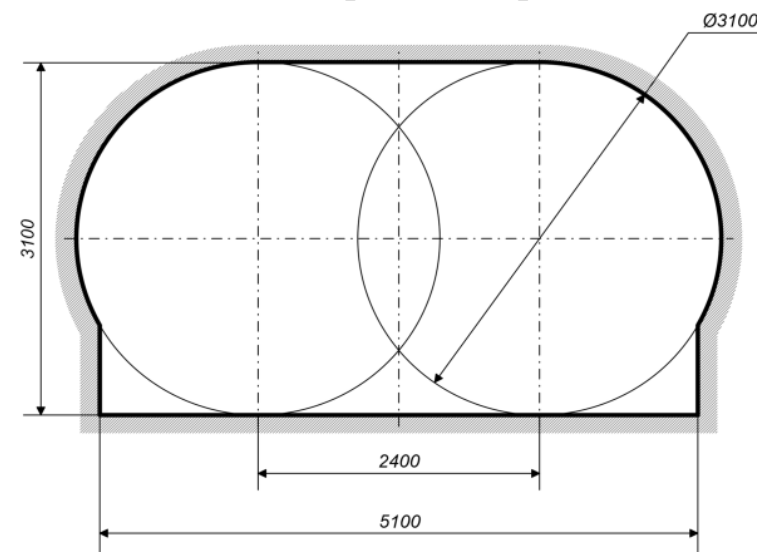

Рис. 2. Геометрия сечения выработки, проходимой комбайном «Урал-20Р»

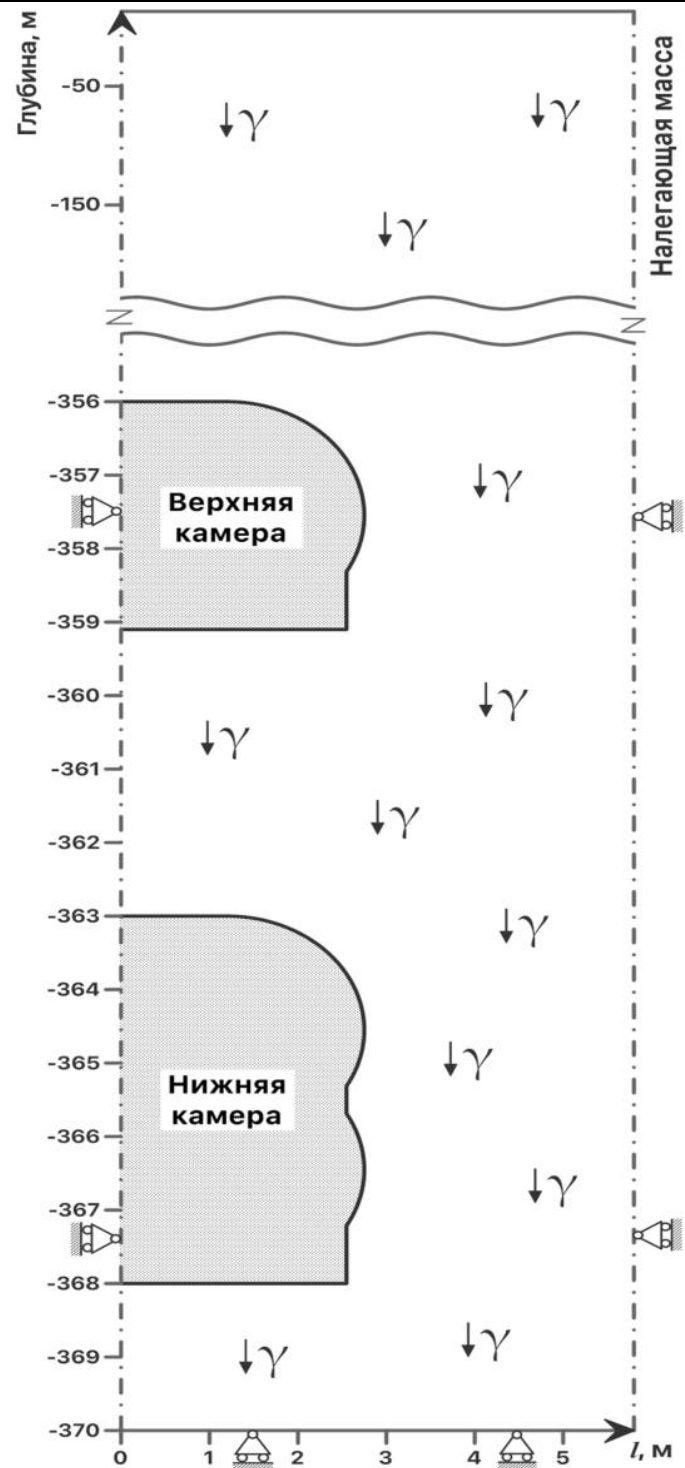

Рис. 3. Принциипиальная расчётная схема

сжатие обусловливает активизацию процесса разрушения целиков в основном за счёт развития трещин сдвига. При этом, как и следовало ожидать, зоны пластичности интенсивнее развиваются в целиках с более высокой степенью нагружения, т.е. на нижнем рабочем пласте.

На рис. 5 иллюстрируется зависимость относительных поперечных деформаций междукамерных целиков от значения предела прочности на сжатие. Начиная с величины предела прочности на сжатие 6,5 МПа отмечается интенсивное нарастание поперечных деформаций на нижнем пласте. Зона разрушения при этом охватывает около половины поперечного сечения целика. Максимальные значения относительной поперечной деформа- 
Параметры отработки

Таблийа 1.

\begin{tabular}{|c|c|c|c|c|}
\hline Камера & $\begin{array}{c}\text { Межосевое } \\
\text { расстояние, } \mathbf{~}\end{array}$ & Ширина камеры, м & Ширина целика, м & Высота целика, м \\
\hline Верхняя & 11,6 & 5,1 & 6,5 & 3,1 \\
\hline Нижняя & 11,6 & 5,1 & 6,5 & 5,0 \\
\hline
\end{tabular}

Механические параметры материала

\begin{tabular}{|c|c|c|c|}
\hline Модуль Юнга, ГПа & Коэффициент Пуассона & $\boldsymbol{\sigma}_{\mathrm{c}}$, МПа & $\boldsymbol{\sigma}_{\mathrm{t}, \text { МПа }}$ \\
\hline 1,0 & 0,3 & 15,0 & 1,0 \\
\hline
\end{tabular}
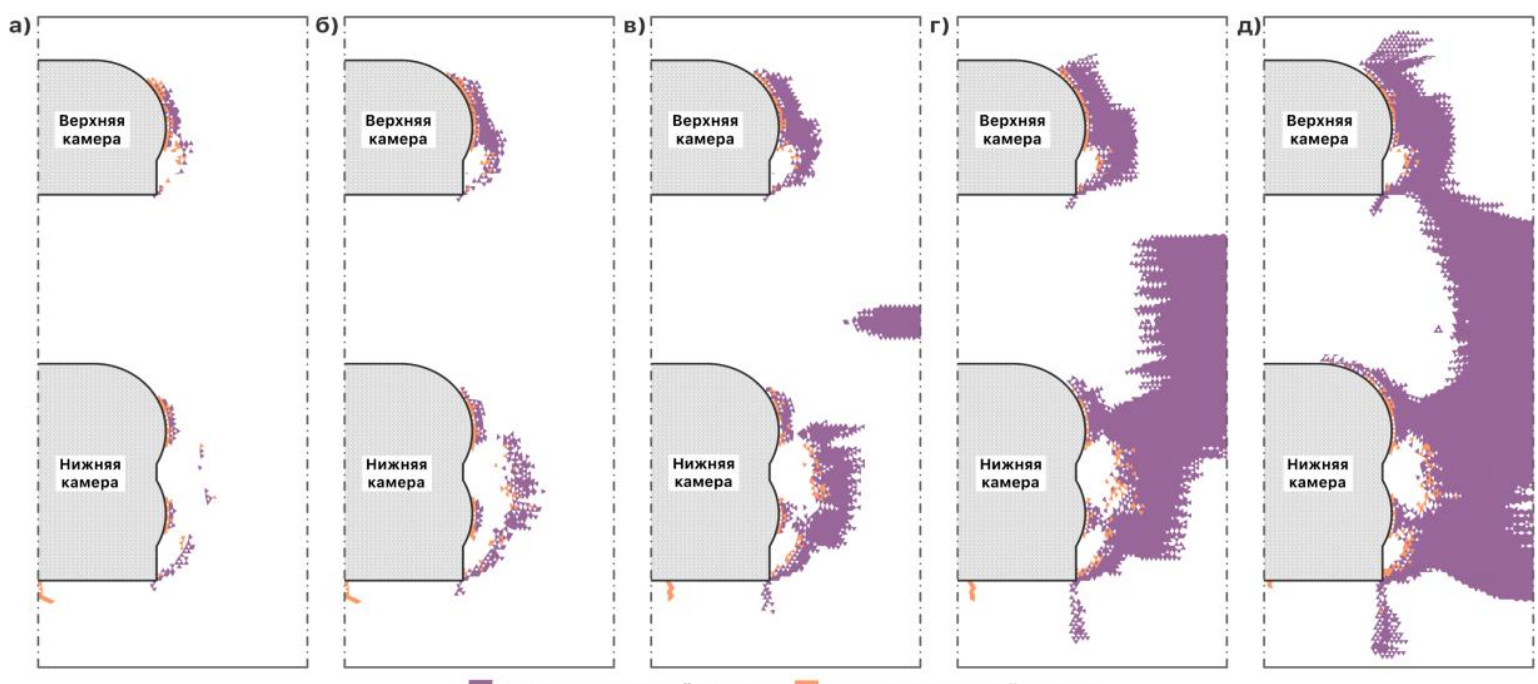

- разрушение за счёт сдвига - разрушение за счёт отрыва

Рис. 4. Характер развития зон пластичности (разрушения) в междукамерных целиках:

a) $\sigma_{c}=9,0$ МПа; б) $\sigma_{c}=8,0$ МПа; в) $\sigma_{c}=7,0$ MПа; г) $\sigma_{c}=6,0$ MПа;д) $\sigma_{c}=5,4$ MПа

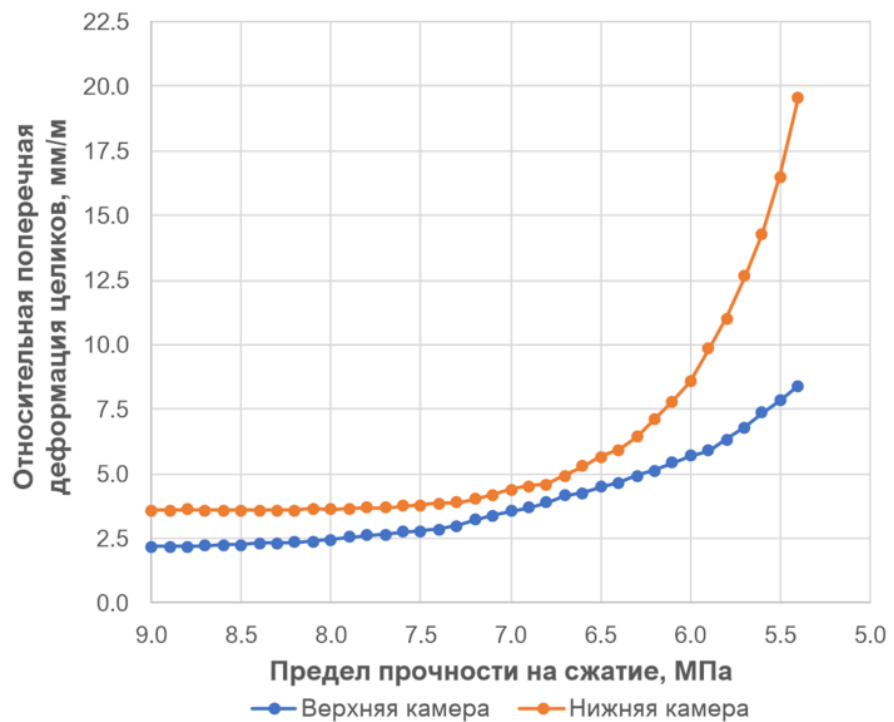

Рис. 5. Зависимость относительных поперечных деформаций междукамерных ичеликов от значения предела прочности на сжатие 
ции, когда разрушению подвержена большая часть целика на нижнем пласте составляет практически 20 мм/м, что соответствует значению предела прочности на сжатие 5,4 МПа. Вместе с тем зависимость относительных поперечных деформаций от предела прочности на сжатие для верхнего пласта имеет более пологий вид. Вероятно, это обусловлено тем, что в расчётах не была достигнута величина предела прочности на сжатие, при котором зона пластического деформирования охватывает большую часть целика на верхнем пласте. Отметим, что напряженно-деформированное состояние целика на нижнем пласте, в отличие от верхнего, достаточно близко к одноосному сжатию. В этом случае предел прочности, при котором происходит асимптотическое нарастание поперечных деформаций (полное разрушение междукамерного целика) является аналогом предела длительной прочности при одноосном сжатии. По результатам компьютерного моделирования (см. рис. 5) асимптотическое значение предела прочности на сжатие $\sigma_{c}=5,2 \mathrm{MПа.}$ Соответственно отношение этой величины к начальному значению $\sigma_{c}=15 \mathrm{MПа}$, определенному в результате теоретического описания результатов лабораторных экспериментов, представляет собой коэффици- ент длительной прочности и составляет 0,347, что полностью согласуется с данными лабораторных исследований соляных пород на ползучесть [2].

Таким образом, на основе модифицированного критерия прочности Боткина и Миролюбова построена упругопластическая модель среды с упрочнением, адекватно отражающая характер разрушения междукамерных целиков с учетом их геометрического строения. По результатам численных исследований установлено, что при развитии зоны пластического деформирования, охватывающей около половины поперечного сечения целиков, происходит резкое увеличение значений относительных поперечных деформаций МКЦ. Учитывая простоту организации регулярных наблюдений за величиной относительных поперечных деформаций МКЦ в шахтных условиях Верхнекамского месторождения, данный параметр можно использовать для оперативной оценки устойчивого состояния опорных элементов подземных сооружений. Расчётный предел прочности, при котором реализуется асимптотическое увеличение поперечных деформаций, соответствует полному разрушению междукамерных целиков и является аналогом предела длительной прочности.

\section{Библиографический список}

1. Баклашов И.В. Геомеханика: учебник для вузов. В 2 т. / - М.: Изд-во Московского государственного горного университета, 2004. - Т. 1. Основы геомеханики. -208 с.

2. Барях А.А., Асанов В.А., Паньков И.Л. Физико-механические свойства соляных пород Верхнекамского калийного месторождения: учеб. пособие /. - Пермь: изд-во Перм. гос. техн. ун-та, 2008. - 199 с.

3. Барях А.А., Самоделкина Н.А. Об одном критерии прочности горных пород // Чебышевский сборник. - 2017. - Т. 18. - № 3 (63). - C. 72-87. - DOI: 10.22405/2226-8383-2017-18-3-72-87

4. Временная инструкция по расчету целиков для пологопадающих залежей на глубине более 400 м и наклонных залежей Жезказганского месторождения / Корпорация «Казахмыс». Алматы-Жезказган, 1998. - 158 с.

5. Евсеев A.B., Удариев А.A. Методика определения нормативной скорости поперечного деформирования междукамерных целиков в лабораторных условиях // Горное эхо. - 2019. - № 3. C. 31-34. https://doi.org/10.7242/echo.2019.3.8.

6. Методические рекомендации к «Указаниям по защите рудников от затопления и охране подрабатываемых объектов в условиях Верхнекамского месторождения калийных солей». Введ. в действие с 30.03.2017 в ред. 2014 г. - Пермь; Березники, 2014.

7. Методическое руководство по выбору геомеханических параметров технологии разработки угольных пластов короткими забоями. - СПб.: ВНИМИ, 2003. - 30 с.

8. Протосеня А.Г., Шоков А.Н. Расчет параметров целиков при камерно столбовой системе разработки рудных месторождений с использованием трехмерных моделей // Горный журнал. 2015. - № 11. - С. 20-23.

9. Указания по защите рудников от затопления и охране подрабатываемых объектов на Верхнекамском месторождении калийно-магниевых солей: утв. ПАО «Уралкалий», ЗАО 
«Верхнекамская калийная компания», ООО «ЕвроХим-Усольский Калийный комбинат». - введ. в действие 30.03.2017 в ред. 2014 г. - Пермь; Березники, 2014. - 130 с.

10. Черепов А.А., Ширяев С.Н., Кулак В.Ю. Обоснование геомеханических параметров камерной системы разработки мощного пологого угольного пласта // Горный информационно-аналитический бюллетень. - 2017. - № 9. - С. 161-169.

11. de Souza Neto Eduardo A., Peric Djordje, Owen David R. J. Computational Methods for Plasticity: Theory and Applications. - John Wiley \& Sons Ltd. - Chichester, 2008. - 814 p.

12. Hudeček V., Šancer J., Zubiček V., Golasowski J. Experience in the Adoption of Room and Pillar Mining Method in the Company OKD, a.s., Czech Republic // Journal of Mining Science. - 2017. - Vol. 53. P. 99-108.

13. Napa-Garcia G.F., Câmara T.R., Torres V.F.N. Optimization of room-and-pillar dimensions using automated numerical models. // International Journal of Mining Science and Technology. - 2019. - Vol. 29. - Iss. 5. P. 797-801.

14. Zienkiewicz O.C., Taylor R.L., Zhu J.Z. The finite element method: Its basis and fundamentals. $7^{\text {th }}$ ed. Butterworth-Heinemann, Oxford, 2013.

15. Zienkiewicz O.C., Taylor R.L., Fox D.D. The finite element method for solid and structural mechanics. $7^{\text {th }}$ ed. - Butterworth-Heinemann, Waltham, 2014.

\title{
PHYSICAL AND MATHEMATICAL MODELLING OF RIB PILLAR DEFORMATION AND FAILURE PROCESSES
}

\author{
I.S. Lomakin, A.A. Tsayukov, A.V. Evseev
}

Mining Institute UB RAS

\section{For citation:}

Lomakin I.S., Tsayukov A.A., Evseev A.V. Physical and mathematical modelling of rib pillar deformation and failure processes /I Perm Federal Research Center Journal. - 2021 . № 1. - P. 47-53. https://doi.org/10.7242/2658-705X/2021.1.4

Underground mining of water-soluble ores is associated with the necessity of mine protection from flooding. Reduction of risks of emergency situations at Perm Krai potash mining enterprises by means of real-time response to underground changes and by organizing appropriate preventive measures contributes to safe subsoil usage and the development of the region.

The article presents the main results of research on experimental and theoretical justification for using relative transversal deformation of rib pillars as an informative parameter that allows a rapid assessment of underground mine load-carrying elements for Verkhnekamskoye potash deposit conditions.

Experimental studies consisted of physical modelling of pillars deformation and failure processes on the basis of laboratory tests on uniaxial loading of salt rock cubic specimens of large sizes with simultaneous recording of their strain state. Theoretical studies included mathematical description of laboratory tests results and determination of medium model parameters that could reliably describe all stages of salt sample deformation. In order to estimate rib pillars relative transversal deformation values at which yield occurs the adaptation of developed model of medium to stoping room supporting elements taking into account their real size and geometrical form was carried out.

Keywords: salt rocks, rib pillars, mathematical modelling, strength criterion, failure, transversal deformation, load-carrying capacity.

\section{Сведения об авторах}

Ломакин Иван Сергеевич, кандидат технических наук, научный сотрудник, Горный институт Уральского отделения Российской академии наук - филиал Федерального государственного бюджетного учреждения науки Пермского федерального исследовательского центра Уральского отделения Российской академии наук («ГИ УрО РАН»), 614007, г. Пермь, ул. Сибирская, д.78-A; e-mail: Lomakin@Mi-Perm.ru

Цаюков Андрей Андреевич, инженер, «ГИ УрО РАН»; e-mail: andrei.tsayukov@inbox.ru

Евсеев Антон Владимирович, кандидат технических наук, научный сотрудник, «ГИ УрО РАН»; e-mail: Evseev@Mi-Perm.ru 